\title{
ANALISIS KELAYAKAN FINANSIAL UNIT USAHA JASA MESIN PENANAM PADI (Rice Transplanter) DI KECAMATAN SEPUTIH RAMAN KABUPATEN LAMPUNG TENGAH
}

\author{
(Financial Feasibility Analysis of Rice Planting Machine (Rice Transplanter) in Seputih Raman Subdistrict \\ Central Lampung Regency)
}

Bernadus Bagus Prabowo, Wan Abbas Zakaria, Teguh Endaryanto

Jurusan Agribisnis, Fakultas Pertanian, Universitas Lampung, J1. Prof. Dr. Soemantri Brojonegoro No. 1 Bandar Lampung, 35145, Telp. 085769554040, e-mail : bernadusprabowo02@gmail.com

\begin{abstract}
This study aims to analyze: the financial feasibility and the sensitivity of rice transplanter business unit. The location is purposively selected in Seputih Raman Subdistrict, Central Lampung Regency. This research uses a census method with 3 respondents owners of rice transplanters of two differences in machinery investment, i.e, the year of 2014 and 2015.. Data are analyzed quantitatively using measurement criteria for financial and sensitivity analysis. The results showed that the rice transplanter business unit is financially viable. The machine of rice planting business unit (rice transplanter) is still feasible despite the drop harvest area of $6.83 \%$, the assumption of a decrease in rental rate machine of 5\%, and the increase in operating costs of $3.85 \%$.
\end{abstract}

Key words: financial, rice transplanter, sensitivity

\section{PENDAHULUAN}

Provinsi Lampung merupakan salah satu sentra produksi padi nasional, sebagai penunjang kebutuhan beras nasional, pada tahun 2015 produksi padi Provinsi Lampung berada di urutan ke-7 dengan produksi 3,64 juta ton atau sekitar $4,85 \%$ produksi nasional (BPS 2015).

Pangan merupakan kebutuhan rakyat yang ketersediaan, distribusi dan tingkat harganya sangat berpengaruh pada stabilitas perekonomian nasional. Ketersediaan pangan yang lebih kecil dibandingkan dengan kebutuhan masyarakat dapat menciptakan ketidakstabilan ekonomi. Salah satu pangan yang dikonsumsi masyarakat Indonesia adalah beras. Kebutuhan beras sebagai salah satu sumber pangan utama masyarakat Indonesia terus meningkat, hal ini karena jumlah penduduk terus bertambah (1,3\% per tahun) dan adanya perubahan pola konsumsi dari non beras ke beras. Dipihak lain, khususnya di Pulau Jawa terjadi penciutan lahan sawah akibat konversi lahan untuk kepentingan non pertanian (Litbang Pertanian 2008).

Kabupaten Lampung Tengah merupakan salah satu kabupaten yang ada di Provinsi Lampung dengan luas lahan dan jumlah produksi tanaman padi terbesar di Lampung. Diharapkan Kabupaten Lampung Tengah bisa menjadi lumbung padi bagi pemenuhan kebutuhan pangan beras di Provinsi
Lampung maupun Indonesia. Kecamatan Seputih Raman merupakan wilayah yang mempunyai lahan sawah terbesar di Kabupaten Lampung Tengah dengan jumlah total luas lahan 7.025 hektar dengan jumlah lahan padi sawah 6.756 hektar

Keterbatasan tenaga kerja merupakan faktor yang mempengaruhi kegiatan usahatani padi. Dalam budidaya padi, salah satu kegiatan yang banyak menyerap tenaga kerja adalah kegiatan menanam bibit padi. Dampak dari kelangkaan tenaga kerja tanam padi antara lain mengakibatkan jadwal tanam sering mundur dan tanam tidak serentak sehingga berpengaruh terhadap indeks penanaman padi. Gangguan OPT yang berpengaruh terhadap produksi padi. Berdasarkan Renstra Kementrian Pertanian (2012) pemerintah mencanangkan pentingnya adanya mekanisasi pertanian seperti mesin tanam padi (rice transplanter), yang diharapkan dapat meningkatkan indeks penanaman tanaman pangan dan pengendalian OPT

Inovasi teknologi rice transplanter berpeluang dapat mempercepat waktu tanam padi dan mengatasi kelangkaan tenaga kerja tanam padi pada daerah-daerah tertentu. Usahatani padi memiliki beberapa tahapan salah satu diantaranya adalah sistem penanaman, Penanaman yang dilakukan oleh petani padi adalah dengan menggunkan tenaga kerja manusia. Pada musim tanam padi ketersediaan tenaga kerja tanam sangatlah terbatas. Biasanya kegiatan tanam padi 
dilakukan oleh ibu ibu yang memiliki usia 40 sampai 60 tahun. Tanaman padi biasanya dilakukan penanaman serentak agar bisa mengendalikan adanya OPT yang dapat mempengaruhi produktivitas hasil panen padi.

Berdasarkan uraian latar belakang masalah maka, penelitian ini bertujuan untuk mengkaji kelayakan finansial dan sensitivitas kelayakan finansial unit usaha mesin tanam rice transplanter dan melihat aspek kelembagaan pada usaha jasa mesin tanam padi di Kecamatan Seputih Raman Kabupaten Lampung Tengah.

\section{METODE PENELITIAN}

Penelitian ini dilakukan di Kecamatan Seputih Raman Kabupaten Lampung Tengah. Lokasi penelitian dipilih secara sengaja (purposive) dengan pertimbangan bahwa Kecamatan Seputih Raman merupakan daerah yang potensial untuk meningkatkan produksi padi karena memiliki areal sawah yang terluas di Kabupaten Lampung Tengah dan terdapat petani yang menggunakan mesin tanam padi rice transplanter

Responden dalam penelitian ini diambil dengan metode sensus. Responden yang diteliti adalah seluruh petani yang memiliki mesin rice transplanter sebanyak 3 responden. Mesin yang diteliti adalah mesin dengan tahun investasi 2014 dan 2015 dengan status mesin milik pribadi dan bantuan dari pemerintah. Data yang dikumpulkan dalam penelitian ini meliputi data primer dan data sekunder.

Data primer diperoleh melalui wawancara secara langsung dengan pemilik mesin. Data sekunder diperoleh dari studi literatur, laporan-laporan, publikasi, artikel dan pustaka yang berhubungan serta lembaga atau instansi yang terkait.

Metode analisis data yang digunakan adalah metode tabulasi dan komputasi. Data yang diperoleh diolah secara kuantitatif. Analisis kuantitatif digunakan untuk mengkaji kelayakan finansial dan sensitivitas unit usaha mesin rice transplanter

\section{Analisis Kelayakan Finansial}

Kelayakan unit usaha mesin rice transpalanter dapat dilihat melalui beberapa kriteria pengukuran kelayakan investasi. Menurut Kadariah (2001), alat yang digunakan untuk menganalisis kelayakan usaha adalah Net Present Value, Internal Rate of Return, Gross Benefit Cost Ratio, Net Benefit Cost
Ratio dan Payback Period. Berdasarkan penelitian yang telah dilakuakan, mesin tanam padi rice transpalanter di Kecamatan Seputih Raman dengan tahun investasi 2014 dan 2015. Data Biaya dan peneriman hanya ada 3 tahun dan 2 tahun sedangkan umur ekonomis mesin 5 tahun. Sehingga untuk data biaya dan penerimaan selanjutnya selama umur ekonomis mesin rice transplanter selama umur ekonomis mesin yakni 5 tahun digunakan analisis trend linear sehingga didapatkan data biaya dan penerimaan unit usaha mesin rice transpalanter. Rumus analisis trend yang digunakan menurut (Kasmir 2008), yaitu:

$y=a+b x$

Keterangan :

$\mathrm{y}=$ Nilai trend untuk jumlah BBM, hari kerja/tanam dan luas lahan tanam

$\mathrm{x}=$ Trend waktu tertentu

$\mathrm{a}=$ Intercept (nilai trend $\mathrm{y}$, pada saat $\mathrm{x}=0$ )

$\mathrm{b}=$ Konstanta

Analisis kelayakan finansial unit usaha mesin penanam padi rice transplanter menggunakan tingkat suku bunga dasar kredit (SBDK) Retail yaitu sebesar 9,75\% (BRI 2016).

\section{a. Net Present Value (NPV)}

NPV dihitung berdasarkan selisih antara benefit dengan biaya (cost) ditambah dengan investasi, yang dihitung melalui rumus:

$\mathrm{NPV}=\sum_{t=1}^{n} \frac{\mathrm{Bt}-\mathrm{Ct}}{(1+\mathrm{i})^{\mathrm{t}}}$

Keterangan :

$\mathrm{NPV}=$ Net Present Value

$\mathrm{Bt}=$ Benefit (penerimaan) bersih tahun $\mathrm{t}$

$\mathrm{Ct}=$ Cost (biaya) pada tahun $\mathrm{t}$

$\mathrm{i}=$ Tingkat suku bunga $(\%)$

$\mathrm{n}=$ Umur ekonomis mesin rice transplanter

$\mathrm{t}=$ Tahun

Kriteria pengambilan keputusan:

1) Jika NPV >0, maka Mesin rice transplanter layak untuk diusahakan

2) Jika NPV $=0$, maka Mesin rice transplanter dalam keadaan titik impas (BEP)

3) Jika NPV < 0, maka Mesin rice transplanter tidak layak untuk diusahakan 


\section{b. Internal Rate of Return (IRR)}

Internal Rate of Return (IRR) merupakan suatu tingkat bunga yang menunjukkan NPV sama dengan jumlah seluruh investasi atau dengan kata lain tingkat suku bunga yang menghasilkan NPV sama dengan nol. IRR dihitung dengan menggunakan rumus sebagai berikut:

$\mathrm{IRR}=\mathrm{i}^{-}+\left[\frac{\mathrm{NPV}^{+}}{\mathrm{NPV}^{+}-\mathrm{NPV}^{-}}\right]\left(\mathrm{i}^{-}-\mathrm{i}^{+}\right)$

Keterangan :

IRR = Internal Rate of Return

$\mathrm{NPV}^{+}=\mathrm{NPV}$ positif

$\mathrm{NPV}^{-}=\mathrm{NPV}$ negatif

$\mathrm{i}^{+} \quad=$ Tingkat suku bunga pada NPV positif

$\mathrm{i}^{-} \quad=$ Tingkat suku bunga pada NPV negarif

Kriteria pengambilan keputusan:

1) Jika IRR > tingkat suku bunga, maka usaha rice transplanter layak untuk diusahakan.

2) Jika IRR = tingkat suku bunga, maka usaha rice transplanter dalam keadaan impas.

3) Jika IRR < tingkat suku bunga, maka usaha rice transplanter tidak layak untuk diusahakan.

\section{c. Gross Benefit Cost Ratio (Gross B/C)}

Gross Benefit Cost Ratio digunakan untuk melihat perbandingan antara nilai penerimaan kotor dengan nilai biaya tunai kotor, yang dihitung berdasarkan rumus:

Gross B/C $=\frac{\sum_{t=1}^{n} \frac{\mathrm{Bt}}{(1+\mathrm{i})^{\mathrm{t}}}}{\sum_{t=1}^{n} \frac{\mathrm{Ct}}{(1+\mathrm{i})^{\mathrm{t}}}}$

Keterangan :

Gross B/C = Gross Benefit Cost Ratio

$\mathrm{B}_{\mathrm{t}} \quad=$ Benefit (penerimaan)

$\mathrm{C}_{\mathrm{t}} \quad=$ Cost (biaya)

$\mathrm{i}=$ Tingkat suku bunga $(\%)$

$\mathrm{n}=$ Umur ekonomis rice

$\begin{array}{ll} & \text { transplanter } \\ \mathrm{t} \quad & \text { Tahun }\end{array}$
Kriteria pengambilan keputusan:

1) Jika Gross $\mathrm{B} / \mathrm{C} \geq 1$, maka Mesin rice transplanter menguntungkan

2) Jika Gross $\mathrm{B} / \mathrm{C}<1$, maka Mesin rice transplanter tidak menguntungkan.

\section{d. Net Benefit Cost Ratio (Net B/C)}

Nilai kriteria ini melihat perbandingan antara nilai penerimaan tunai dan nilai pengeluaran atau biaya tunai, yang dihitung berdasarkan rumus :

Net $\mathrm{B} / \mathrm{C}=\frac{\sum_{t=1}^{n} \frac{\mathrm{Bt}-\mathrm{Ct}}{(1+\mathrm{i})^{\mathrm{t}}}}{\sum_{t=1}^{n} \frac{\mathrm{Ct}-\mathrm{Bt}}{(1+\mathrm{i})^{\mathrm{t}}}}$

Keterangan :

Net $\mathrm{B} / \mathrm{C}=$ Net Benefit Cost Ratio

$\mathrm{B}=$ Benefit (penerimaan) bersih tahun $\mathrm{t}$

$\mathrm{C}_{\mathrm{t}}=$ Cost (biaya) pada tahun $\mathrm{t}$

$\mathrm{i}=$ Tingkat suku bunga (\%)

$\mathrm{n}=$ Umur ekonomis rice transplanter

$\mathrm{t}=$ Tahun

Kriteria pengambilan keputusan:

1) Jika Net $\mathrm{B} / \mathrm{C} \geq 1$, maka Mesin rice transplanter menguntungkan

2) Jika Net $\mathrm{B} / \mathrm{C}<1$, maka Mesin rice transplanter tidak menguntungkan

e. Payback Period (PP)

Payback period dihitung dengan membandingkan antara penilaian investasi suatu proyek yang didasarkan pada pelunasan biaya investasi awal dengan manfaat bersih (benefit) dari suatu proyek dalam satu satuan waktu yang dapat dirumuskan sebagai berikut:

$\mathrm{PP}=\frac{\mathrm{I}_{0}}{\mathrm{~A}_{\mathrm{b}}}$

Keterangan:

$\mathrm{Pp}=$ Payback period

$\mathrm{I}_{0} \quad=$ investasi awal

$\mathrm{A}_{\mathrm{b}}=$ manfaat bersih rata-rata

Kriteria pengambilan keputusan:

1) Jika nilai $\mathrm{Pp}<$ dari umur ekonomis Mesin Rice Transplanter, maka Mesin rice transplanter layak untuk dilaksanakan. 
2) Jika nilai $\mathrm{Pp}>$ dari umur ekonomis Mesin rice transplanter maka Mesin rice transplanter tidak layak untuk dilaksanakan.

Analisis sensitivitas adalah suatu analisa untuk dapat melihat pengaruh- pengaruh yang akan terjadi akibat keadaan yang berubah-ubah (Gittinger 1986). Penerimaan dan biaya yang dikeluarkan mempengaruhi kriteria pengukuran kelayakan. Perubahan kedua aspek tersebut secara otomatis akan merubah nilai-nilai kriteria investasi. Aspek analisis sensitivitas yang akan dianalisis pada penelitian ini diantaranya adalah:

a. Penurunan luasan lahan tanam sebesar $6,83 \%$ dihitung dari rata-rata penurunan luasan lahan tanam mesin setiap tahun dikarenakan semakin tuanya umur mesin rice transplanter.

b. Penurunan harga sewa mesin dikarenakan kemungkinan persaingan harga persewaan mesin antara pemilik mesin yaitu sebesar $5 \%$.

c. Terjadi perubahan biaya sebesar $3,85 \%$ yang disebabkan karena adanya inflasi.

Aspek di atas sama dengan yang dilakukan oleh Rosepa, et al. (2014). Rumus yang digunakan untuk mengkaji analisis sensitivitas adalah:

Laju Kepekaan $=\frac{\frac{X_{1}-X_{0}}{X_{f}} \times 100 \%}{\frac{Y_{1}-Y_{0}}{Y_{f}} \times 100 \%}$.

Kriteria pengambilan keputusan laju kepekaan adalah:

1) Jika laju kepekaan $>1$, maka unit usaha mesin combine harvester peka atau sensitif terhadap perubahan
2) Jika laju kepekaan < 1, maka unit usaha mesin combine harvester tidak peka atau tidak sensitif terhadap perubahan

\section{HASIL DAN PEMBAHASAN}

\section{Keadaan Umum Responden}

Responden pada penelitian ini berjumlah 3 orang pemilik mesin tanam padi (rice transplanter). Umur responden 33-55 tahun, tingkat pendidikan responden SMA dan Sarjana. Pekerjaan sampingan responden wirausaha dan berternak.

\section{Biaya Investasi}

Biaya investasi adalah biaya yang dikeluarkan oleh pelaku usaha untuk keperluan pembelian mesin tanam padi rice transplanter sebagai modal awal untuk melakukan usaha penyewaan mesin tanam padi. Mesin yang ada pada penelitian ini memiliki tahun investasi 2014 dan 2015. Untuk mesin tahun 2014 status kepemilikannya adalah milik pribadi sedangkan untuk mesin tahun 2015 salah satunya merupakan bantuan dari pemerintah yang disalurkan kepada gapoktan di Kecamatan Seputih Raman Kabupaten Lampung Tengah. Harga mesin dengan tahun investasi 2014 dan 2015 yakni Rp64.000.000,00 per mesin

Berdasarkan Tabel 1. dapat dilihat biaya investasi dan biaya oprasional mesin rice transplanter untuk tahun investasi 2014 sebesar Rp126.815.300,00 dan untuk mesin tahun investasi 2015 milik pribadi sebesar Rp136.537.400,00 dan mesin tahun investasi 2015 milik kelompok sebesar Rp144.633.250,00 dapat dilihat bahwa mesin dengan tahun investasi 2015 biaya investasi dan oprasional lebih besar dikarenakan areal tanam lebih luas.

Tabel 1. Total biaya investasi dan biaya operasional unit usaha mesin rice transplanter selama umur ekonomis mesin rice transplanter 5 tahun

\begin{tabular}{cccc}
\hline \multirow{2}{*}{ Tahun } & \multicolumn{3}{c}{ Biaya Total Tahun Investasi } \\
\cline { 2 - 4 } & 2014 (pribadi) & 2015 (pribadi) & 2015 (kelompok) \\
\hline 1 & $71.692 .500,00$ & $72.093 .000,00$ & $73.000 .350,00$ \\
2 & $10.380 .950,00$ & $12.719 .600,00$ & $14.007 .500,00$ \\
3 & $13.867 .850,00$ & $13.896 .200,00$ & $15.564 .650,00$ \\
4 & $14.570 .300,00$ & $18.072 .800,00$ & $20.041 .800,00$ \\
5 & $16.303 .700,00$ & $19.755 .800,00$ & $22.018 .950,00$ \\
\hline Total & $126.815 .300,00$ & $136.537 .400,00$ & $144.633 .250,00$ \\
\hline
\end{tabular}


Tabel 2. Penerimaan total unit usaha persewaan mesin rice tansplanter di Kecamatan Seputih Raman

\begin{tabular}{cccr}
\hline \multirow{2}{*}{ Tahun } & \multicolumn{3}{c}{ Penerimaan Tahun Investasi } \\
\cline { 2 - 4 } & 2014 (pribadi) & 2015 (pribadi) & 2015 (kelompok) \\
\hline 1 & $18.000 .000,00$ & $16.800 .000,00$ & $22.200 .000,00$ \\
2 & $25.050 .000,00$ & $34.200 .000,00$ & $42.000 .000,00$ \\
3 & $39.900 .000,00$ & $51.600 .000,00$ & $62.400 .000,00$ \\
4 & $49.200 .000,00$ & $69.000 .000,00$ & $82.200 .000,00$ \\
5 & $67.000 .000,00$ & $92.800 .000,00$ & $109.000 .000,00$ \\
\hline Total & $199.150 .000,00$ & $264.400 .000,00$ & $317.800 .000,00$ \\
\hline
\end{tabular}

\section{Biaya Operasional}

Biaya oprasioal dan pemeliharaan ialah biaya yang dikeluarkan oleh pemilik jasa penyewaan mesin yang rutin dalam setiap aktifitas mesin saat melakukan pekerjaan ataupun saat melakukan pemeliharaan mesin. Biaya biaya itu adalah bahan bakar minyak (BBM), biaya pelumas, biaya tenaga kerja, dan biaya sevice mesin selama umur ekonomis mesin 5 tahun.

Bahan bakar yang digunakan mesin tanam padi rice transplanter adalah premium kapasitas tangki mesin untuk bahan bakar 5 liter tenaga yang dimiliki mesin tanam 7 HP (horse power). Harga bahan bakar untuk mesin dengan tahun investasi 2014 Rp6.450,00 per liter tahun investasi 2015 Rp6.450,00 per liter. Mesin tanam membutuhkan beberapa pelumas untuk melakukan kegiatannya diantaranya, yaitu oli mesin, oli gardan dan oli hidrolik. Harga pelumas/oli mesin Rp30.000,00/liter, harga per liter oli gardan Rp45.000,00, dan harga satu liter oli hidrolik Rp35.000,00. Tenaga kerja yang dibutuhkan untuk oprasional mesin 2 orang, 1 operator mesin dan 1 helper. Biya yang dikeluarkan untuk tenaga kerja adalah operator Rp100.000,00, dan untuk helper Rp80.000,00 tenaga kerja berasal dari tenaga kerja luar keluarga.

Pemeliharaan mesin dilakukan rutin oleh pemilik mesin, pemeliharaan dilakukan setiap awal musim tanam. Pemeliharaan dilakukan antara lain mesin penggerak, pabel, roda, papan seluncur, dan jarum. Biaya yang harus dikeluarkan untuk pemeliharaan mesin Biaya pemeliharaan mesin setiap kali melakukan pemeliharaan Rp750.000,00, pemeliharaan panbel Rp525.000,00, pemeliharaan roda Rp300.000,00, pemeliharaan pegantian papan seluncur mesin rice transplanter sebesar Rp1.200.000,00, pemeliharaan jarum penanam Rp240.000,00.

Penerimaan yang diperoleh unit usaha jasa persewaan mesin rice tansplanter tahun investasi 2014 milik pribadi sebesar Rp199.150.000,00 dengan jumlah lahan tanam sebesar 321,25 hektar dengan harga sewa mesin rice tansplanter Rp600.000,00/hektar, penerimaan mesin tahun investasi 2015 pribadi sebesar Rp264.400.000,00 dengan jumlah lahan tanam 430 hektar dengan harga sewa rata rata mesin Rp600.000,00/hektar dan penerimaan mesin tahun investasi 2015 kelompok sebesar Rp317.800.000,00 dengan jumlah lahan tanam 519 hektar dengan harga sewa rata rata mesin Rp600.000,00/hektar dapat dilihat bawa mesin denga tahun investasi 2015 memiliki penerimaan lebih tinggi dibandingkan dengan mesin 2014 karena mesin tahun 2015 memperoleh luas lahan lebih besar sehingga berpengaruh terhadap penerimaan.

\section{Analisis Kelayakan Finansial}

Perhitungan analisis kelayakan finansial usaha jasa sewa mesin tanam padi rice transplanter dengan umur ekonomis 5 tahun dihitung dengan discounting pada tingkat suku bunga $9,75 \%$ yang merupakan suku bunga dasar kredit

Hasil dari penelitian ini sejalan dengan penelitian Suhendrata (2013) prospek pengembangan mesin tanam pindah bibit padi dalam rangka mengatasi kelangkaan tenaga kerja tanam bibit padi di Jawa Tengah. Menyimpulkan bahwa kehadiran rice transplanter pada kondisi lahan sawah datar, petakan luas dan kedalaman lumpur kurang dari $40 \mathrm{~cm}$ dapat membantu memecahkan masalah kekurangan tenaga tanam pindah bibit padi. Usaha jasa rice transplanter layak dijalankan dan dikembangkan dengan $N P V$ selama 5 tahun pada tingkat bunga modal $12 \%$ adalah Rp22,4 juta, IRR $=59,59 \%$, gross $B / C=1,26$ dan $P P=2,42$ tahun. Tanam menggunakan rice transplanter dapat meningkatkan pendapatan usahatani padi sebesar Rp2.690.000/ha/musim tanam dengan marginal $\mathrm{B} / \mathrm{C}$ sebesar 23,42 sehingga tanam menggunakan rice transplanter sangat layak untuk diterapkan secara luas. Penggunaan rice transplanter dapat menguntungkan kedua belah pihak yaitu pemberi jasa (pemilik rice transplanter) dan pengguna jasa (petani pengguna rice transplanter). 
Tabel 3. Analisis Finansial unit usaha persewaan mesin rice tansplanter tahun investasi 2014 dan 2015 dengan tingkat suku bunga $9,75 \%$

\begin{tabular}{|c|c|c|c|c|}
\hline \multirow{2}{*}{$\begin{array}{c}\text { Analisis } \\
\text { Finansial }\end{array}$} & \multicolumn{3}{|c|}{ Hasil } & \multirow{2}{*}{ Keterangan } \\
\hline & 2014 pribadi & 2015 pribadi & 2015 kelompok & \\
\hline NPV & $51.100 .602,16$ & $92.686 .225,33$ & $132.316 .160,49$ & layak \\
\hline IRR & $36 \%$ & $56 \%$ & $77 \%$ & layak \\
\hline Gross B/C & 1,37 & 1,69 & 1,93 & layak \\
\hline Net B/C & 1,79 & 2,53 & 3,37 & layak \\
\hline $\mathrm{PP}$ & 2,57 & 1,25 & 1,01 & layak \\
\hline
\end{tabular}

\section{Analisis Sensitivitas}

Menurut Astanu, Ismono, Rosanti (2013), analisis sensitivitas adalah kegiatan menganalisis kembali suatu proyek, untuk melihat yang akan terjadi pada proyek tersebut bila tidak berjalan sesuai rencana dan menyebabkan terjadinya kemunduran dari berjalannya proyek yang disebabkan faktor ketidakpastian yang mempengaruhi biaya dan penerimaan. Analisis sensitivitas bisa dilihat pada Tabel 4. menunjukkan perubahan-perubahan yang dikaji dalam analisis sensitivitas unit usaha mesin tanam padi ini yaitu penurunan luas lahan panen padi sebesar $6,83 \%$, penurunan harga sewa mesin sebesar 5\% dan kenaikan biaya sebesar 3,85\% karena adanya inflasi. Analisis sensitivitas menunjukkan pada tiap tahun investasi mesin 2014 dan 2015 menunjukkan bahwa pada saat luas panen turun sebesar 6,83\% dan asumsi harga sewa mesin turun sebesar $5 \%$ dan biaya naik karena inflasi 3,85 \% kecuali mesin 2015, semua kriteria baik Net Present Value, Internal Rate of Return, Gross B/C Ratio, dan Net B/C Ratio sensitif terhadap perubahan dengan nilai laju kepekaan >1, kecuali Payback Period yang menunjukkan nilai laju kepekaan $<1$. Sebaliknya analisis sensitivitas kenaikan biaya sebesar 3,85\% karena adanya inflasi pada unit usaha mesin tanam padi dengan tahun investasi 2015 adalah sebaliknya, yaitu nilai Payback Period sensitif terhadap perubahan dengan nilai laju kepekaan $>1$, sedangkan nilai Net Present Value, Internal Rate of Return, Gross B/C Ratio, dan Net B/C Ratio tidak sensitif terhadap perubahan karena nilai laju kepekaannya menunjukkan nilai $<1$.

Tabel 4. Analisis sensitivitas unit usaha persewaan mesin rice tansplanter tahun investasi 2014 pribadi, 2015 pribadi dan 2015 kelompok

\begin{tabular}{|c|c|c|c|c|c|c|c|c|c|c|}
\hline \multirow{2}{*}{ Kriteria } & \multirow{2}{*}{ Nilai Awal } & \multicolumn{3}{|c|}{ luas tanam turun $6,83 \%$} & \multicolumn{3}{|c|}{ Harga turun $5 \%$} & \multicolumn{3}{|c|}{ Biaya naik $3,85 \%$} \\
\hline & & Perubahan & Lk & Ket & Perubahan & $\mathrm{Lk}$ & Ket & Perubahan & Lk & Ket \\
\hline \multicolumn{11}{|c|}{ Tahun investasi 2014 pribadi } \\
\hline NPV & $51.100 .602,16$ & $38.521 .008,14$ & 3,97 & S & $41.891 .186,44$ & 3,86 & S & $46.215 .461,82$ & $-2,90$ & TS \\
\hline IRR & $36 \%$ & $29 \%$ & 2,74 & $S$ & $31 \%$ & 2,70 & S & $33 \%$ & $-2,72$ & TS \\
\hline \multicolumn{11}{|l|}{ Gros } \\
\hline $\mathrm{B} / \mathrm{C}$ & 1,37 & 1,28 & 0,97 & S & 1,30 & 0,97 & S & 1,32 & $-1,00$ & TS \\
\hline Net B/C & 1,79 & 1,58 & 1,74 & S & 1,64 & 1,74 & S & 1,68 & $-1,79$ & TS \\
\hline PP & 2,57 & 4,85 & $-8,68$ & TS & 4,85 & $-11,96$ & $\mathrm{TS}$ & 4,90 & 17,96 & $\mathrm{~S}$ \\
\hline \multicolumn{11}{|c|}{ Tahun investasi 2015 pribadi } \\
\hline NPV & $92.686 .225,33$ & $71.126 .101,30$ & 3,72 & $S$ & $75.194 .137,12$ & 4,06 & S & $87.940 .063,97$ & $-1,52$ & TS \\
\hline IRR & $56 \%$ & $45 \%$ & 3,01 & $S$ & $47 \%$ & 3,34 & $S$ & $52 \%$ & $-1,98$ & TS \\
\hline \multicolumn{11}{|l|}{ Gros } \\
\hline $\mathrm{B} / \mathrm{C}$ & 1,69 & 1,51 & 1,63 & S & 1,53 & 1,88 & S & 1,63 & $-1,00$ & TS \\
\hline Net B/C & 2,53 & 2,13 & 2,41 & S & 2,20 & 2,69 & S & 2,53 & 0,00 & TS \\
\hline $\mathrm{PP}$ & 1,25 & 2,86 & $-11,10$ & TS & 2,87 & $-15,3$ & $\mathrm{TS}$ & 2,87 & 22,66 & $\mathrm{~S}$ \\
\hline \multicolumn{11}{|c|}{ Tahun investasi 2015 kelompok } \\
\hline NPV & $132.316 .160,49$ & $113.938 .160,54$ & 2,11 & S & $118.862 .280,59$ & 2,09 & S & $127.317 .582,13$ & $-1,11$ & TS \\
\hline IRR & $77 \%$ & $68 \%$ & 1,86 & $\mathrm{~S}$ & $70 \%$ & 1,85 & $\mathrm{~S}$ & $72 \%$ & $-1,85$ & TS \\
\hline \multicolumn{11}{|l|}{ Gros } \\
\hline $\mathrm{B} / \mathrm{C}$ & 1,93 & 1,80 & 0,98 & S & 1,84 & 0,98 & $\mathrm{~S}$ & 1,87 & $-1,00$ & $\mathrm{TS}$ \\
\hline Net B/C & 3,37 & 2,98 & 1,73 & $S$ & 3,09 & 1,73 & $\mathrm{~S}$ & 3,17 & 0,00 & $\mathrm{TS}$ \\
\hline $\mathrm{PP}$ & 1,01 & 1,47 & $-5,29$ & TS & 1,48 & $-7,39$ & TS & 1,49 & 11,04 & $\mathrm{~S}$ \\
\hline
\end{tabular}


Tabel 5. Perbandingan kelembagaan pribadi dan kelompok tani Rice Transplanter di Kecamatan Seputih Raman

\begin{tabular}{lll}
\hline \multicolumn{1}{c}{ Kriteria } & Pribadi & Kelompok Tani \\
\hline Wilayah & Lingkungan pemilik mesin & Anggota kelompok tani dan lingkungan terdekat \\
Peraturan & Tenaga kerja dipilih pemilik & Tenaga kerja dipilih ketua yang berasal dari \\
& mesin & anggota kelompok tani \\
Hak dan Kewajiban & $\begin{array}{l}\text { Pembayaran upah tenaga } \\
\text { kerja dan pemeliharaan mesin }\end{array}$ & $\begin{array}{l}\text { Pembayaran upah tenaga kerja, pemeliharaan } \\
\text { mesin, pemberian upah kepada bendahara dan } \\
\text { sekertaris. }\end{array}$ \\
& Biaya Rp 600.0000 diberikan & Biaya Rp 600.0000 diberikan sebagai pembayaran \\
Pembayaran jasa & sebagai pembayaran jasa & jasa dan masuk sebagai kas gapoktan \\
\hline
\end{tabular}

\section{Analisis Kelembagaan}

Analisis kelembagaan yang dimaksud terkait dengan pengaturan pelaksanaan operasional usaha (enforcement), batas wilayah kerja, hak dan kewajiban pemilik mesin kepada tenaga kerja, serta peraturan dalam pembayaran jasa mesin rice transplanter. Pada Tabel 5. menjelaskan bahwa usaha persewaan mesin rice transplanter dapat dikelola dan dijalankan dengan baik. Kelembagaan persewaan mesin rice transplanter. Hal hal yang terkait dalam kelembagaan mesin rice transplanter pengaturan pelaksanaan operasional usaha (enforcement), batas wilayah kerja, hak dan kewajiban pemilik mesin kepada tenaga kerja, serta peraturan dalam pembayaran jasa mesin rice transplanter. Kelembagaan yang dilakukan oleh pengelola unit usaha persewaan mesin rice transplanter dibedaka menjadi dua bagian yaitu pemilik mesin pribadi dan pemilik mesin kelompok tani.

\section{KESIMPULAN}

Analisis usaha penyewaan mesin tanam padi rice transplanter secara finansial layak diusahakan. Unit usaha ini tetap layak diusahakan meski terjadi penurunan luas lahan kurang dari 6,83\%, penurunan harga sewa mesin $5 \%$ dan kenaikan biaya $3,85 \%$. Sistem kelembagaan pada usaha penyewaan mesin tanam padi masih tergolong sederhana dalam skala rumah tangga.

\section{DAFTAR PUSTAKA}

Astanu DA, Ismono RH, dan Rosanti N. 2013. Analisis kelayakan finansial budidaya intensif tanaman pala di Kecamatan Gisting
Kabupaten Tanggamus. JIIA, 1(3): 218-225. http://jurnal.fp.unila.ac.id/ index.php/JIIA/ article/view/576/538. [14 Januari 2018].

BPS [Badan Pusat Statistik]. 2015. Produksi, Luas Lahan Panen dan Produktivitas Padi Berdasarkan Provinsi Tahun 2015. BPS. Jakarta.

BRI [Bank Rakyat Indonesia]. 2016. Suku bunga dasar kredit. http//bri.co.id/resource/ sbdk.ap. [11 November 2016].

Gittinger JP. 1986. Analisa Ekonomi ProyekProyek Pertanian. Edisi Kedua. Universitas Indonesia. Jakarta.

Kadariah. 2001. Evaluasi Proyek Analisis Ekonomi. Lembaga Penerbit Fakultas Ekonomi UI. Jakarta.

Kasmir. 2008. Analisis Laporan Keuangan. Rajawali Press. Jakarta.

Kementerian Pertanian. 2012. Strategi dan Inovasi Mekanisasi Teknologi Pertanian. Kementrian Pertanian. Jakarta.

Litbang Pertanian. 2008. Pengelolaan Tanman Terpadu (PTT) padi gogo. Badan Litbang Pertanian

Rosepa P, Affandi MI, dan Adawiyah R. 2014. Analisis kelayakan usaha pengembangan agroindustri gula kelapa skala mikro di Kabupaten Lampung Timur, JIIA. 2(2):150157. http://jurnal.fp.unila.ac.id/index.php/JI IA/article/view/739/680. [22 januari 2018].

Suhendrata T. 2013. Prospek pengembangan mesin tanam pindah bibit padi dalam rangka mengatasi kelangkaan tenaga kerja tanam bibit padi. Jurnal ISSN Vol 10, No 1 September 2013. BPTP. Jawa Tengah. http://agribisnis.fp.uns.ac.id/wpcontent/uploa ds/2014/02/11-prospek mesin-tanam-pindahbibit-padi.pdf. [2 Oktober 2017]. 